\title{
Unraveling the Appropriate Dose for Infusion of Human Umbilical Cord Blood Derived Mononuclear Cells in Alleviating Hyperoxia Induced Lung Injury in Neonatal Mice
}

\section{Xue Du}

7th Medical Center of Chinese PLA General Hospital

Jia Chen ( $\square$ jadachenjia@hotmail.com )

7th Medical Center of Chinese PLA General Hospital

\section{Yuhan Chen}

7th Medical Center of Chinese PLA General Hospital

Xiaojuan Yin

7th Medical Center of Chinese PLA General Hospital

\section{Xing Zhang}

7th Medical Center of Chinese PLA General Hospital

\section{Xiao Yang}

7th Medical Center of Chinese PLA General Hospital

\section{Zhichun Feng}

7rd Medical Center of Chinese PLA General Hospital

\section{Research}

Keywords: Bronchopulmonary Dysplasia, Cord blood, Mononuclear cell, Cytokines, Newborn

Posted Date: July 26th, 2021

DOI: https://doi.org/10.21203/rs.3.rs-736730/v1

License: (a) (i) This work is licensed under a Creative Commons Attribution 4.0 International License. Read Full License 


\section{Abstract}

Background: Intravenous infusion of human umbilical cord blood derived mononuclear cells (hUCBMNCs) alleviates the hyperoxia-induced neonatal lung injury. The aim of this preclinical study was to determine the optimal dose of hUCB-MNCs in alleviating hyperoxia-induced lung injury in neonatal mice.

Method: Newborn C57BL6/J mice were randomly exposed to hyperoxia $\left(85 \% \mathrm{O}_{2}\right)$ or normoxia $\left(21 \% \mathrm{O}_{2}\right)$ after birth for 14 days. Three different doses of hUCB-MNCs, $3 \times 10^{6}$ cells $/ \mathrm{kg}$ (D1), $3 \times 10^{6}$ cells $/ \mathrm{kg}$ (D2), and $3 \times 10^{6}$ (D3), were administered intravenously at postnatal day 7(P7). At P28, lungs were harvested for analyses including morphology for alveolarization, pulmonary function assessment for lung motion and lung blood flow, expression of inflammatory factors and growth factors including TNF-a, IL-1 $\beta$, IL-6, IL-2, IL-10, MMP9, TGF- $\beta$ and VEGF.

Result: We discovered that hyperoxia-induced lung injuries, such as reduced alveolarization, as evidenced by increased mean chord length (MCL) and radical alveolar area (RAA) and decreased radical alveolar counts (RAC) were significantly restored in D1, D2 and D3, with the best in D3. Enhanced expression of TNF- $\alpha$, IL-1 $\beta$, IL-6 concomitant with attenuated expression of IL-10 and IL-2 were shown in all groups with the most significance in D3. Down-regulated expression of TGF- $\beta$, MMP9 and up-regulated expression of VEGF in lung tissue were observed in all groups, with the largest extent in D3.

Conclusion: Collectively, our study revealed the appropriate dose of intravenous infusion of hUCB-MNCs in alleviating hyperoxia-induced lung injury through modulating inflammatory responses and oxidative stress in neonatal mice.

\section{Introduction}

Extreme preterm infants are at a high risk for developing bronchopulmonary dysplasia (BPD), which is characterized by alveolar simplification, development retardation, impaired vascularization, progenitor cell reduce as well as pulmonary function abnormality, leading to chronic oxygen supplementation until late infancy and lifelong disturbances in pulmonary function and neurodevelopment [1]. Conventional managements for BPD are symptom-targeted whereas the mortality rate remains at high levels with survivors displaying systematic adverse effects[2]. Therefore, developing novel and efficient therapies to reduce overall morbidity and improve lifelong quality in extreme preterm infants with BPD are of great significance.

Mononuclear cells (MNCs) are source of stem cell reservior containing high level of primitive multi-potent stem cells, progenitor cells and regulatory T cells [3]. Among various sources including the bone marrow derived mononuclear cells (BM-MNCs), the peripheral blood-derived mononuclear cells (PB-MNCs) and cord blood-derived mononuclear cells (CB-MNCs). Human umbilical cord blood derived MNCs (hUCBMNCs) is considered a promising source for human MNCs due to its easy availability, high proliferation capacity [4,5], and less immunogenicity[5]. A wide range of preclinical studies, clinical trials and case analysis have revealed that MNCs with adult-appendage derivations are capable of presenting superior 
biological activity and regenerative efficacy in adult pulmonary conditions [6-8]. BPD has several characteristics of adult pulmonary diseases, therefore MNCs may have the capacity to attenuate BPD as well. So far, only three studies have examined the translational potential of hUCB-MNCs in neonatal BPDlike animal models. In a study by Ahn et al.[9], the MNCs did not show obvious beneficial effects. In contrast, a study by Monz et al. demonstrated significant improvement of lung architecture [10]and a study by Mills et al. suggested that the MNCs had the capacity to attenuate bronchial hyperreactivity[11]. It is therefore worthwhile to determine the regulatory functions of hUCB-MNCs animal model. HUCBMNCs, which contain proliferative mesenchymal-like cells [4], are easily separated by low-cost and direct physical means, and can be administered easily and safely within hours or days after birth in sufficient quantities to produce immediate effects without requiring expansion. A previous study demonstrated that cells were most prevalent in the microcirculation of lungs by 24 hours and only in the lungs eight weeks after intravenous administration of MNCs to newborn mice [11]. Additionally, the pulmonary engraftment rate was determined to be very low in a study with an experimental model using MNCs [11]. The critical downstream mechanisms are not likely related to pulmonary engraftment and regeneration of damaged structures, but more likely related to the release of paracrine immune factors like cytokines and growth factors by MNCs $[5,11]$. Thus, hUCB-MNCs may represent a cell type-specific therapy for BPD.

Given that hUCB-MNCs intravenous infusion could be a novel therapy for BPD by the above evidence. It is therefore of urgent need to unravel the optimal dose for its administration. We thus tried to determine the appropriate dose at which intravenously infused human hUCB-MNCs improve the hyperoxia-induced lung iinjury in newborn mice in the study.

\section{Materials And Methods}

\section{Study approval and ethics statement}

Animal procedures were reviewed and approved by the Animal Care and Ethic Committee of seventh medical center of PLA General Hospital (No. 2021-026). All animals were housed, cared for, and used in compliance with the guidelines regarding the humane use and care of laboratory animals for biomedical research published by the National Institutes of Health (No. 85-23, revised 1996).

\section{Cell Preparation}

Human umbilical cord blood (UCB) units were supplied by Shandong Qilu stem cell engineering Co. Ltd. For the extraction of hUCB-MNCs, the cryopreserved cord blood units were thawed immediately and gently shook in a $37^{\circ} \mathrm{C}$ water. Cord blood was collected into $50 \mathrm{ml}$ centrifuge tube thrice volume of premixed suspension buffer. This procedure was completed within 5 minutes and the collected UCB was stored at room temperature. Mononuclear cells were isolated by centrifugation over a Ficoll-Hypaque density gradient at 700 rpm for $20 \mathrm{~min}$ at $4^{\circ} \mathrm{C}$ in premixed suspension buffer. Cells at the interface were collected by adding premixed suspension buffer followed by centrifugation at $500 \mathrm{rpm}$ for $5 \mathrm{~min}$ at $4^{\circ} \mathrm{C}$. The collected cells were washed thrice with PBS and subsequently re-suspended in serum-free DMEM. The morphology of re-suspended mononuclear cells were determined by Wright's-Giemsa staining. 


\section{Mice model}

All experimental mice maintained on a C57BL6/J background were purchased from Beijing Vital River Laboratory Animal Technology and housed under pathogen-free conditions. All the mice that were used in the experiments were male. Newborn pups were delivered spontaneously and reared with their dams. The experiment began within 24h after birth and continued through postnatal day 14 (P14). Newborn pups were randomly assigned to five groups: normoxia group (NG), hyperoxia group (HG), hyperoxia with $3 \times 10^{\wedge}$ cells $/ \mathrm{kg}$ (D1), $3 \times 10^{\wedge 5}$ (D2), or $3 \times 10^{\wedge} 6$ (D3) hUCB-MNCs administration group. NG newborn pups were kept with a nursing mother in standard cage at room air throughout the experiment, while HG newborn pups were maintained with a nursing mother in standard carge within 100L Plexiglas chambers in which the hyperoxia $\left(85 \% \mathrm{O}_{2}\right)$ condition was maintained. Humidity and environmental temperature were maintained at $50 \%$ and $24^{\circ} \mathrm{C}$. Nursing mother mice were rotated daily between litters in the normoxia and hyperoxia groups to avoid oxygen toxicity. Survival and body weights of mice pups in each group were checked daily throughout the experiment. The mice pups were sacrificed at P28 under anesthesia ( $5 \%$ Chloal Hydrate, $0.06 \mathrm{ml} / 10 \mathrm{~g}$ ) for evaluating pulmonary motion function, pulmonary blood flow, and whole lung tissue was obtained for morphometric and biochemical analyses.

\section{Infusion of hUCB-MNCs}

Hyperoxia exposed pups at P7 were further randomly assigned to receive hUCB-MNCs intravenous infusion. For cell administration, $3 \times 10^{\wedge} 4(\mathrm{D} 1), 3 \times 10^{\wedge}(\mathrm{D} 2)$, or $3 \times 10^{\wedge} 6(\mathrm{D} 3)$ cells $/ \mathrm{kg}$ in $0.03 \mathrm{ml}(\mathrm{PBS}, \mathrm{pH} 7.4)$ were delivered intravenously to pups by injections through great saphenous vein. For NG and HG, equal volume of saline was given intravenously. For blinding of above experiments, mice were body-tagged with simple numbers. The person who performed the experiments did not know the identity of the specific samples until data were collected and analyzed. After the procedure, the animals were returned to their dams.

\section{Tissue Preparation}

Resected lungs were snap-frozen and stored at $-80^{\circ} \mathrm{C}$ for later biochemical analyses. For morphometric analyses, lungs were fixed in situ by tracheal instillation of $4 \%$ buffered formalin at a constant inflation pressure of $20 \mathrm{cmH}_{2} \mathrm{O}$, and then fixed overnight at room temperature in the same fixative. The fixed lung tissue was embedded in paraffin wax after tissue processing. Sections ( $5 \mu \mathrm{m}$ thick) were stained with hematoxylin and eosin. Images of each section were captured with a magnifier digital camera through an Nikon Eclipse TE300 microscope, and were saved as TIF files.

\section{Lung morphology}

Left-lobe lung sections were stained with H\&E. For each morphometric analysis, sections with large airways or blood vessels were excluded. 4-6 areas per slide were quantitated and averaged per slide. Images were acquired with a Nikon Eclipse TE300 inverted microscope and Hammamatsu C4742 digital camera, using Metamorph software (Universal Imaging, Westchester, PA) and quantification was 
performed using ImageJ version 1.45 ( $\mathrm{NIH}$, Bethesda, MD; http://imagej.nih.gov/ij). For radial alveolar counts (RAC) measurement, the well-established method to quantify alveolarization [12] areas were randomly chosen and photographed at $\times 10$ magnification. For each of six images, a perpendicular line was drawn from the centre of a bronchial or bronchiolar airway to either the edge of the lung or the nearest connective tissue septum or airway. A minimum of 40 lines was drawn for each lung, and the number of septae intersected was counted for each line. Mean chord length $\left(L_{m}\right)(M C L)$ of the airspace was estimated, as previously described $[13,14]$. Briefly, the images were superimposed on parallel on a grid with parallel lines spaced at 58 um intervals and the mean length of each chord, defined as the distance between two sequential intersections of the alveolar surface with the test line, was measured. For measuring the radical alveolar area (RAA) [15], the Analyze Particles function of Image $J$ was used in conjunction with a custom written macro for the measurement of the lung architecture and alveolar area. To prevent inadvertent observer bias, an investigator blinded to the assigned groups performed image acquisition and analyses. Values were pooled for each individual animal for statistical analysis.

\section{Transmission electron microscopy}

Three slices of $2 \mathrm{~mm} \times 2 \mathrm{~mm} \times 2 \mathrm{~mm}$ were cut from three different segments of the left lung and fixed in $2.5 \%$ glutaraldehyde and phosphate buffer $0.1 \mathrm{M}(\mathrm{pH}=7.4)$ for electron microscopy analysis. For each lung electron microscopy image (20/animal), the following alterations were analyzed as described previously [16]: (a) alveolar-capillary membrane damage, (b) type II pneumocyte lesion, (c) type I pneumocytes infiltration, (d) elastic fiber breakdown, (e) capillaries and fibroblasts deposition. Data were acquired using JEOL 1010 Transmission Electron Microscope, Tokyo, Japan.

\section{Pulmonary function assessment}

For detection of respiratory motion function, mice were euthanized with $4 \%$ chloral hydrate $(0.01 \mathrm{ml} / \mathrm{g})$ i.p followed by tracheostomy. Data were monitored and acquired by Acqknowledge (Biopac systems. Inc., USA), a pulmonary maneuver system. During data collection, basic stable HR (heart rate) was recorded by ECG before tracheotomy operation. Mice HR were maintained at proper level ( $<10 \%$ variation of basic HR) and breathing rate were maintained stable to ensure the reliability of the physiological data. Basic parameters including peak inspiratory flow (PIF), peak expiratory flow (PEF), tidal volume (TV), breathing per minute (BPM) and minute volume (MV).

For detection of pulmonary blood flow, all mice subsequently transferred to evaluate pulmonary blood flow with laser doppler flowmetry (LDF) using Moor FLPI (Moor Instruments, UK). Mice were ventilated (Alcott biotech, China) with an average breathing frequency of 150 breaths/min, inspiratory/expiratory ratio 2.0 and tidal volume $1.0 \mathrm{ml} / \mathrm{kg}$. The blood flow of bilateral lungs and heart were synchronizing measured after they were fully exposed. The pulmonary blood flow signal intensity was normalized to heart surface blood.

\section{Immuno-histochemistry}


The lung tissue were paraffined and sectioned into $5 \mu \mathrm{m}$ slides. Subsequently, the sections were stained with indiacated primary antibodies followed by HRP-conjugated secondary antibodies and developed with DAB substrate (brown). Images were obtained under the Nikon Bx60 microscope connected to a Nikon DP70 camera with Cell-F imaging software (Soft Imaging System). All staining was assessed by a quantitative imaging method using image $\mathrm{J}$ software; the percentage of immunostaining and the staining intensity were recorded. An $\mathrm{H}$ score was calculated using the following formula: $\mathrm{H}$-score $=\Sigma(P|x|)=$ (percentage of cells of weak intensity $\times 1)+($ percentage of cells of moderate intensity $\times 2)+($ percentage of cells of strong intensity $\times 3$ ). $\mathrm{PI}$ indicates the percentage of positive cells versus all cells.

\section{RNA extraction and real time PCR}

Total RNA was isolated using Trizol method and reverse transcribed to cDNA using the ReverTra Ace® kit (Toyobo, TRT-101). Quantitative real-time PCR reactions were conducted using SYBR Green PCR master mix (Toyobo, QPK201) through ABI QSFlex6 system. Primers were shown in table below.

\section{Result}

\section{Construction of the hyperoxia induced BPD model}

HG significantly decreased body shape and body weight at P7 of experiment compared to NG (HG vs NG: $2.85 \pm 0.36 \mathrm{~g}$ vs $4.52 \pm 0.38 \mathrm{~g}, p \otimes 0.05$ ) (Fig. $1 \mathrm{a}, \mathrm{b}, \mathrm{c}$ ). In this model, expectedly lung morphology analysis revealed disruption of normal alveolar development in $\mathrm{HG}$, characterized by severe impairment of alveolar growth, large airspaces, and incomplete alveolar septation at P7 of experiment (Fig.1d).

\section{Body Weight Gain and Survival Rate}

Birth weights were not significantly different between the five experimental groups in P1 $(3.18 \pm 0.17 \mathrm{~g}$ and $3.22 \pm 0.13 \mathrm{~g}$ in NG and HG, respectively). However, body weight at P28 in HG was significantly lower compared to NG $(10.83 \pm 0.52 \mathrm{~g}$ vs $15.77 \pm 0.36 \mathrm{~g}, P<0.001)$. The reduced body weight gain observed in HG was significantly improved in D1, D2 and D3 (D1 vs HG: $15.773 \pm 0.36 \mathrm{~g}$ vs $10.83 \pm 0.52 \mathrm{~g}, p \rrbracket 0.05$; D2 vs HG: $16.49 \pm 0.34 \mathrm{~g}$ vs $10.83 \pm 0.52 \mathrm{~g}, p \rrbracket 0.05$; D3 vs HG: $17.24 \pm 0.53 \mathrm{~g}$ vs $10.83 \pm 0.52 \mathrm{~g}, p \rrbracket 0.05$, respectively). The seeming gain body weight in D3 and D2 compared to NG did not reach a statistical significance ( $p<0.05$, vs. NG), but not in D1 (Fig. 2a).

HG significantly increased mortality by the end of experiment (P28) compared to the zero mortality of NG. The increased mortality observed in $\mathrm{HG}(p<0.05$, vs. NG) was significantly decreased with hUCB-MNCs treatment in D3 ( $p<0.05$, vs. HG) but not in D1 and D2 ( $p>0.05$, vs. HG) (Fig. 2b). The seeming lower mortality in D3 and D2 compared to NG did not reach a statistical significance ( $p<0.05$, vs. NG), but not in D1 (Fig, 2b囚.

\section{Lung Histopathology}


Impaired alveolar growth, as evidenced by microvascular hyperemia and dilatation, adjacent alveolar fusion, alveolar structure destruction and simplification, inflammatory cell exudation, lung tissue structure disorder, was observed in HG compared to NG. After hUCB-MNCs treatment, hyperoxia-induced impairments in alveolar growth and morphological changes were improved, showing significant attenuation in D1, D2 and D3, with the best attenuation in D3 (Fig.3a). In morphometric analyses, the MCL and RAA mean alveolar area, indicating the chord length and size of the alveoli, respectively (Fig. 3 b,d), were significantly higher in HG $\left(189.67 \pm 33.93 \mu \mathrm{m}\right.$ in MCL and $0.97 \pm 0.27 \mathrm{~mm}^{2}$ in RAA, $\left.p<0.001\right)$ than in NG $\left(60.56 \pm 10.02 \mu \mathrm{m}\right.$ in MCL and $0.39 \pm 0.08 \mathrm{~mm}^{2}$ in RAA, $\left.p<0.001\right)$. The RAC means radical alveolar counts, indicating the volume of the alveoli, was significantly less alveoli in HG than in NG (50.22 $\pm 5.53 / \mathrm{mm}^{2}$ vs $165.78 \pm 10.56 / \mathrm{mm}^{2}, p<0.001$ ) (Fig. 3c). The data demonstrate significant attenuation of decreased MCL in D3 (64.22 $\pm 4.52 \mu \mathrm{m}$ with $66 \%$ attenuation vs HG, $p<0.001)$, in D2 (87.89 $\pm 6.66 \mu \mathrm{m}$ with $54 \%$ attenuation vs $\mathrm{HG}, p<0.001)$, and in D1 (117.22 $\pm 23.82 \mu \mathrm{m}$ with $38 \%$ attenuation vs $\mathrm{HG}, p<$ $0.05)$. Decreased RAA in D3 $\left(0.39 \pm 0.05 \mathrm{~mm}^{2}\right.$ with $60 \%$ attenuation vs HG, $\left.p<0.001\right)$, in D2 $(0.52 \pm$ $0.05 \mathrm{~mm}^{2}$ with $46 \%$ attenuation vs $\left.\mathrm{HG}, p<0.05\right)$ and in $\mathrm{D} 1\left(0.61 \pm 0.13 \mathrm{~mm}^{2}\right.$ with $37 \%$ attenuation vs HG, $p<0.05$ )(Fig. 3d). Increased RAC in D3 (136.78 \pm 5.69 per $\mathrm{mm}^{2}$ with $172 \%$ improvement vs $\mathrm{HG}, p<$ $0.001)$, in $\mathrm{D} 2\left(111.89 \pm 13.27\right.$ per $\mathrm{mm}^{2}$ with $123 \%$ improvement vs $\left.\mathrm{HG}, p<0.001\right)$, and in $\mathrm{D} 1(84.67 \pm 7.07$ per $\mathrm{mm}^{2}$ with $69 \%$ improvement vs $\left.\mathrm{HG}, p<0.001\right)$. These findings support the protection of hUCB-MNCs intravenous infusion with the best result in D3.

\section{Pulmonary motion and respiratory blood flow test}

In line to the alterations in lung morphology, HG displayed shallow and slow breathing, and the lowest number respiratory rate per minute upon hyperoxia exposure, evidencing by the longer expiratory time with small sawtooth wave compared to those in NG. Interestingly, after hUCB-MNCs treatment, hyperoxiainduced impairments in respiratory motion changes was improved, showing different degrees of improvement in D1, D2 and D3, with the most stable sine wave in D3 (Fig.4a). In pulmonary motion analyses, the MV mean dynamic volume of lung, indicating the ventilation of lung, were significantly lower in HG $(8.15 \pm 1.20 \mathrm{ml})$ than in NG $(13.61 \pm 1.74 \mathrm{ml}, p<0.001)$. Our data demonstrate significant improvement of increased MV in D3 (D3 vs HG, $12.53 \pm 1.38 \mathrm{ml}$ vs $8.15 \pm 1.20 \mathrm{ml}, p<0.05$ ), but not in D2 (D2 vs HG, $11.26 \pm 0.45 \mathrm{ml}$ vs $8.15 \pm 1.20 \mathrm{ml}, p>0.05$ ) and D1 (D1 vs HG, $10.87 \pm 0.27 \mathrm{ml}$ vs $8.15 \pm 1.20 \mathrm{ml}$, $p>0.05)$ (Fig.4b).

In order to explore the potential impact of hUCB-MNCs towards peripheral pulmonary vascular remodeling under hyperoxia exposure, lung perfusion with Laser Doppler Flowmetry were employed (Fig. 4c). HG displayed lower left or right lung/heart blood flow ratio compared to that in NG $(p<0.05)$. Our data showed after hUCB-MNCs treatment left or right lung/heart blood flow ratio were improved in P28. In the right lung/heart blood flow ratio was significantly increased in D1 (0.62 \pm 0.13$)$, D2 (0.69 \pm 0.12$)$ and D3 $(0.58 \pm 0.07)$ than that in $\mathrm{HG}(0.36 \pm 0.1, p<0.05)$. But in the left lung/heart blood flow ratio, there was no statistical significance in D1 $(0.70 \pm 0.07)$, D2 $(0.69 \pm 0.03)$ and D3 $(0.73 \pm 0.05)$ than in HG $(0.44 \pm 0.09$, $p>0.05$ ) (Fig.4d). 
In quantitative RT-PCR, significantly increased mRNA levels of TNF-a (HG vs NG: $2.18 \pm 0.58$ vs $1.00 \pm$ $0.13, p<0.05$ ), IL-1 $\beta$ (HG vs NG: $2.80 \pm 0.10$ vs $1.00 \pm 0.00, p<0.05$ ), and IL-6 (HG vs NG, $1.57 \pm 0.09$ vs $1.00 \pm 0.29, p<0.05$ ), were observed in $\mathrm{HG}$ compared to NG. This hyperoxia-induced increase in mRNA expression of these cytokines were significantly attenuated in D2 and D3. TNF-a: D2 vs HG, $0.69 \pm 0.13$ vs $2.18 \pm 0.58, p<0.001$; D3 vs HG, $1.95 \pm 0.42$ vs $2.18 \pm 0.58, p<0.05$ (Fig. $5 \mathrm{a}$ ), IL-1 $\beta$ : D1 vs HG, $0.52 \pm$ 0.09 vs $2.80 \pm 0.10, p<0.05$; D2 vs HG, $2.80 \pm 0.10$ vs $1.03 \pm 0.39, p<0.05$; D3 vs HG, $0.86 \pm 0.15$ vs 2.80 $\pm 0.10, p<0.05$ (Fig. 5 b) and IL-6 :D1 vs HG, $0.81 \pm 0.02$ vs $1.57 \pm 0.09, p<0.05$; D2 vs HG, $0.67 \pm 0.32$ vs $1.57 \pm 0.09, p<0.05$; D3 vs HG, $1.24 \pm 0.01$ vs $1.57 \pm 0.09, p<0.05$ ), but not in D1 (Fig.5c). Hyperoxiainduced decreased in mRNA expression of IL-10 were significantly increased in D1 and D3. D1 vs HG, $0.24 \pm 0.02$ vs $0.65 \pm 0.15, p<0.05$; D3 vs HG, $2.27 \pm 0.15$ vs $0.65 \pm 0.15, p<0.05$ and IL-2 : D3 vs HG, $2.24 \pm 0.41$ vs $0.20 \pm 0.05, p<0.05$ but not in D2 (Fig. 5 d) and IL-10: D2 vs HG, $0.65 \pm 0.03$ vs $0.65 \pm 0.15$, $p>0.05$ ) (Fig.5e).

\section{Cytosolic expression of growth factors MMP9, TGF- $\beta$ and VEGF}

Since vascular remodeling and growth reactivation are the main routine to alleviate hyperoxia induced lung injury $[7,17]$. We systematically examined the protein expression levels of the corresponding cytokines. We observed significantly increased level of MMP9: HG vs NG, $9.14 \pm 1.16$ vs $2.20 \pm 1.04, p<$ 0.05 (Fig. 6a, left panels) and TGF- $\beta$ (HG vs NG, $19.37 \pm 4.08$ vs $7.14 \pm 0.12, p<0.05$ (Fig.6a, middle panels), and decreased level of VEGF were observed in HG: HG vs NG, $8.17 \pm 1.07$ vs $10.40 \pm 0.11, p>$ 0.05 (Fig.6a, right panels). This hyperoxia-induced increase regarding vascular remodeling of these cytokines were significantly attenuated in D1, D2 and D3 (MMP9, D1 vs HG, $1.18 \pm 0.15$ vs $9.14 \pm 1.16$, $p<0.05$; 22 vs $\mathrm{HG}, 1.55 \pm 0.74$ vs $9.14 \pm 1.16, p<0.05 \llbracket \mathrm{D} 3$ vs $\mathrm{HG}, 1.95 \pm 0.15$ vs $9.14 \pm 1.16, p<0.05$; TGF- $\beta$, D1 vs HG, $2.77 \pm 1.35$ vs $19.37 \pm 4.08, p<0.05 \rrbracket \mathrm{D} 2$ vs $\mathrm{HG}, 0.50 \pm 0.38$ vs $19.37 \pm 4.08, p<0.05$; D3 vs HG: $7.19 \pm 7.18$ vs $19.37 \pm 4.08, p<0.05$ ). Hyperoxia-induced abrogation in VEGF were significantly increased in D3 (VEGF, D3 vs HG, $18.29 \pm 1.30$ vs $8.17 \pm 1.07, p<0.05$ ), but not in D1 and D2 (VEGF, D1 vs $\mathrm{HG}, 4.58 \pm 1.10$ vs $8.17 \pm 1.07, p>0.05$; 22 vs $H G, 7.06 \pm 2.35$ vs $8.17 \pm 1.07, p>0.05$ ) (Fig.6b).

\section{Discussion}

In our study, prolonged exposure of newborn wild type $(\mathrm{WT})$ mice to hyperoxia $\left(85 \% \mathrm{O}_{2}\right)$ for 14 days increased mortality [18], retarded growth, and developed lung injuries similar to those seen in the extreme preterm human infants with BPD $[19,20]$, exhibiting decreased alveolarization as evidenced by increased MCL [20] and RAA, and significantly decreased RAC [20] at P28. After hUCB-MNCs treatment, hyperoxia induced damage was improved showing the best result in HT3. Moreover, hUCB-MNCs treatment exhibited the capacity of enhancing the overall lung motion function and maintaining pulmonaryvascular flow homeostasis according to the lung morphology (Fig. 3, 4). Because of technical limitations, a maximum of $3 \times 10^{6} \mathrm{cells} / \mathrm{kg}$ were intravenously infused in the our study. The maximum concentration of hUCB-MNCs without adhesion is $1 \times 10^{8}$ cells $/ \mathrm{ml}$, and $3 \mu \mathrm{l}$ is the maximum volume that could be given 
intravenously to newborn mice pups at P7 that weighed an average of $2.85 \pm 0.36 \mathrm{~g}$ in HG. The maximum number of cells feasible for intravenous infusion in a newborn mice pups was $3 \times 10^{6}$ cells. In our previous study, the cells localized in the lung tissue at P28 was positively associated with the protective effects against hyperoxia-induced lung injuries. Therefore, these evidences indicate that improvement of hyperoxia-induced neonatal lung injuries relates to hUCB-MNCs administered, and that intravenous infusion of $3 \times 10^{6}$ cells $/ \mathrm{kg}$ seems to be the appropriate dose to maximize protective effects in the hyperoxia induced model and setting.

Inflammation is generally considered to be detrimental in recovery from hyperoxia induced lung injuries, but single use of anti-inflammatory treatments targeting specific inflammatory mediators have yet been ineffective. We have detected the factors regarding inflammatory regulation, tissue repair and vascular remodeling (Fig. 5,6). Interestingly, our data of significant increases in IL-1 $\beta$, IL-6, TNF-a, MMP9 and TGF$\beta$ along with decreased in IL-10 and VEGF observed in HG support the assumption that inflammatory responses mediated by inflammatory cytokines and growth factor [21-24] play an important role in the development of BPD. Hyperoxia-induced increase pro-inflammatory and decrease anti-inflammatory were significantly balance in D1, D2 and D3, while D3 show the most stable after hUCB-MNCs infusion. Moreover, the declined TGF- $\beta$ signaling and MMP9 expression along with escalated VEGF expression after hUCB-MNCs treatment implied the prevalence of adopting hUCB-MNCs in both balancing the delicate and intertwining feature of inflammatory networks and rescuing the devastative developing lung in experimental BPD model caused by hyperoxia exposure. Although the mechanisms of this antiinflammatory effects remain to be unclear, we assume that the beneficial outcome might be attributable to paracrine effects as mesenchyme stem cell (MSC) [25], including trophic factor secretion and immunomodulation by cytokines. These findings suggest that the intravenous infusion of $3 \times 10^{6} \mathrm{cells} / \mathrm{kg}$ might be the appropriate cell counts to achieve effective anti-oxidative effects in the model.

\section{Conclusion}

In conclusion, intravenous infusion of hUCB-MNCs significantly attenuated hyperoxia induced lung pathology such as decreased alveolarization in both D1, D2 and D3, with the best protection in D3. The intravenous delivery of at least $3 \times 10^{6}$ cells was the possible dose to achieve effective anti-inflammatory effects and enhancing the lung motion function. Although this dose might be possible for newborn mice, it might not be appropriate to extrapolate these results on a kilogram basis to human newborns. Further studies will be necessary to determine the optimal dose of hUCB-MNCs for potential clinical benefit in human infants with BPD.

\section{List Of Abbreviations}

BPD, Bronchopulmonary Dysplasia; hUCB-MNCs, Human umbilical cord blood derived mononuclear cell; qRT-PCR, quantitative real-time polymerase chain reaction; H\&E, hematoxylin and eosin; PIF, peak 
inspiratory flow; PEF, peak expiratory flow; TV, tidal volume; BPM, breathing per minute; MV, minute volume.

\section{Declarations}

\section{Ethical approval and consent to participate}

Animal procedures were reviewed and approved by the Animal Care and Ethic Committee of seventh medical center of PLA General Hospital (No. 2021-026). All animals were housed, cared for, and used in compliance with the guidelines regarding the humane use and care of laboratory animals for biomedical research published by the National Institutes of Health (No. 85-23, revised 1996).

\section{Consent for publication}

All co-authors have read and approved of its submission to this journal.

\section{Availability of data and materials}

The data and materials used in the current study are all available from the corresponding author upon reasonable request.

\section{Competing interests}

All authors declared that they had no competing conflict of interests to disclose.

\section{Funding information}

This research was jointly granted by National Key R\&D Program of China (2018YFC1002701) and Chinese National Natural Science Foundation Projects (81901518).

\section{Author contributions}

JC and ZCF conceptualized the study. JC, XD and YHC conceived and designed the study. XD, JC and XZ performance of the mice husbandry, BPD animal model, pulmonary function test, and participated in stem cell purification and injection. XD and YHC, performed mRNA expression analysis and immunohistochemistry; XD, JC , XJY and ZCF wrote of the manuscript. All authors read and approved the manuscript.

\section{Acknowledgements}

The authors thank Dr. Xiaolu Shi (Experimental Research Center, China Academy of Chinese Medical Sciences, Beijing, China) for kindly helping them with pulmonary function tests. We also thank Shandong Cord Blood Bank for providing the hUCB-MNCs. 


\section{References}

1. Thebaud B, KN Goss, M Laughon, JA Whitsett, SH Abman, RH Steinhorn, JL Aschner, PG Davis, SA McGrath-Morrow, RF Soll and AH Jobe. (2019). Bronchopulmonary dysplasia. Nat Rev Dis Primers 5:78.

2. Jobe AH. (2011). The new bronchopulmonary dysplasia. Curr Opin Pediatr 23:167-72.

3. Peters EB, B Liu, N Christoforou, JL West and GA Truskey. (2015). Umbilical Cord Blood-Derived Mononuclear Cells Exhibit Pericyte-Like Phenotype and Support Network Formation of Endothelial Progenitor Cells In Vitro. Ann Biomed Eng 43:2552-68.

4. Parekh VS, MV Joglekar and AA Hardikar. (2009). Differentiation of human umbilical cord bloodderived mononuclear cells to endocrine pancreatic lineage. Differentiation 78:232-40.

5. Abreu SC, MA Antunes, L Mendonça, VC Branco, EB de Melo, PC Olsen, BL Diaz, DJ Weiss, BD Paredes, DG Xisto, MM Morales and PR Rocco. (2014). Effects of bone marrow mononuclear cells from healthy or ovalbumin-induced lung inflammation donors on recipient allergic asthma mice. Stem Cell Res Ther 5:108.

6. Machado MN, F Mazzoli-Rocha, NV Casquilho, T Maron-Gutierrez, VH Ortenzi, MM Morales, RS Fortunato and WA Zin. (2018). Bone Marrow-Derived Mononuclear Cell Therapy in Papain-Induced Experimental Pulmonary Emphysema. Front Physiol 9:121.

7. Maron-Gutierrez T, RC Castiglione, DG Xisto, MG Oliveira, FF Cruz, R Pecanha, H Carreira-Junior, DS Ornellas, MO Moraes, CM Takiya, PR Rocco and MM Morales. (2011). Bone marrow-derived mononuclear cell therapy attenuates silica-induced lung fibrosis. Eur Respir J 37:1217-25.

8. Luan Y, Z-H Zhang, D-E Wei, Y Lu and Y-B Wang. Effects of Autologous Bone Marrow Mononuclear Cells Implantation in Canine Model of Pulmonary Hypertension. Japanese Circulation Journal 76:977-985.

9. Ahn SY, YS Chang, DK Sung, HS Yoo, SI Sung, SJ Choi and WS Park. (2015). Cell type-dependent variation in paracrine potency determines therapeutic efficacy against neonatal hyperoxic lung injury. Cytotherapy 17:1025-35.

10. Monz D, E Tutdibi, C Mildau, J Shen, M Kasoha, MW Laschke, T Roolfs, A Schmiedl, T Tschernig, K Bieback and L Gortner. (2013). Human umbilical cord blood mononuclear cells in a double-hit model of bronchopulmonary dysplasia in neonatal mice. PLoS One 8:e74740.

11. Mills DR, Q Mao, S Chu, K Falcon Girard, M Kraus, JF Padbury and ME De Paepe. (2017). Effects of human umbilical cord blood mononuclear cells on respiratory system mechanics in a murine model of neonatal lung injury. Exp Lung Res 43:66-81.

12. Tipple TE, SE Welty, LD Nelin, JM Hansen and LK Rogers. (2009). Alterations of the thioredoxin system by hyperoxia: implications for alveolar development. Am J Respir Cell Mol Biol 41:612-9.

13. Bhandari V, R Choo-Wing, CG Lee, K Yusuf, JH Nedrelow, N Ambalavanan, H Malkus, RJ Homer and JA Elias. (2008). Developmental regulation of NO-mediated VEGF-induced effects in the lung. Am J Respir Cell Mol Biol 39:420-30. 
14. Hansmann G, A Fernandez-Gonzalez, M Aslam, SH Vitali, T Martin, SA Mitsialis and S Kourembanas. (2012). Mesenchymal stem cell-mediated reversal of bronchopulmonary dysplasia and associated pulmonary hypertension. Pulm Circ 2:170-81.

15. Nold MF, NE Mangan, I Rudloff, SX Cho, N Shariatian, TD Samarasinghe, EM Skuza, J Pedersen, A Veldman, PJ Berger and CA Nold-Petry. (2013). Interleukin-1 receptor antagonist prevents murine bronchopulmonary dysplasia induced by perinatal inflammation and hyperoxia. Proc Natl Acad Sci U S A 110:14384-9.

16. Cruz FF, MA Antunes, SC Abreu, LC Fujisaki, JD Silva, DG Xisto, T Maron-Gutierrez, DS Ornellas, VK Sa, NN Rocha, VL Capelozzi, MM Morales and PR Rocco. (2012). Protective effects of bone marrow mononuclear cell therapy on lung and heart in an elastase-induced emphysema model. Respir Physiol Neurobiol 182:26-36.

17. Luan Y, W Ding, ZY Ju, ZH Zhang, X Zhang and F Kong. (2015). Bone marrow-derived mesenchymal stem cells protect against lung injury in a mouse model of bronchopulmonary dysplasia. Mol Med Rep 11:1945-50.

18. Choi CW, BI Kim, EK Kim, ES Song and JJ Lee. (2012). Incidence of bronchopulmonary dysplasia in Korea. J Korean Med Sci 27:914-21.

19. Coalson JJ. (2003). Pathology of new bronchopulmonary dysplasia. Semin Neonatol 8:73-81.

20. Husain AN, NH Siddiqui and JT Stocker. (1998). Pathology of arrested acinar development in postsurfactant bronchopulmonary dysplasia. Hum Pathol 29:710-7.

21. Bhandari V and JA Elias. (2006). Cytokines in tolerance to hyperoxia-induced injury in the developing and adult lung. Free Radic Biol Med 41:4-18.

22. Choo-Wing R, JH Nedrelow, RJ Homer, JA Elias and V Bhandari. (2007). Developmental differences in the responses of IL-6 and IL-13 transgenic mice exposed to hyperoxia. Am J Physiol Lung Cell Mol Physiol 293:L142-50.

23. Marcho Z, JE White, PJ Higgins and MF Tsan. (1991). Tumor necrosis factor enhances endothelial cell susceptibility to oxygen toxicity: role of glutathione. Am J Respir Cell Mol Biol 5:556-62.

24. Warner BB, LA Stuart, RA Papes and JR Wispé. (1998). Functional and pathological effects of prolonged hyperoxia in neonatal mice. Am J Physiol 275:L110-7.

25. Sadan O, E Melamed and D Offen. (2009). Bone-marrow-derived mesenchymal stem cell therapy for neurodegenerative diseases. Expert Opin Biol Ther 9:1487-97.

\section{Table}


Table 1

primers used in qRT-PCR

\begin{tabular}{|lll|}
\hline IL-2 & TCCAGAACATGCCGCAGAG & CCTGAGCAGGATGGAGAATTACA \\
\hline IL-6 & TAGTCCTTCCTACCCCAATTTCC & TTGGTCCTTAGCCACTCCTTC \\
\hline IL-1 $\beta$ & CTCCATGAGCTTTGTACAAGG & TGCTGATGTACCAGTTGGGG \\
\hline IL-2 & TCCAGAACATGCCGCAGAG & CCTGAGCAGGATGGAGAATTACA \\
\hline IL-10 & GACCCTCACACTCAGATCATC & GAACCTGG GAGTAGATAAGG \\
\hline GAPDH & AGGTCGGTGTGAACGGATTTG & TGTAGACCATGTAGTTGAGGTTTTCA \\
\hline
\end{tabular}

Figures 
figure 1

a

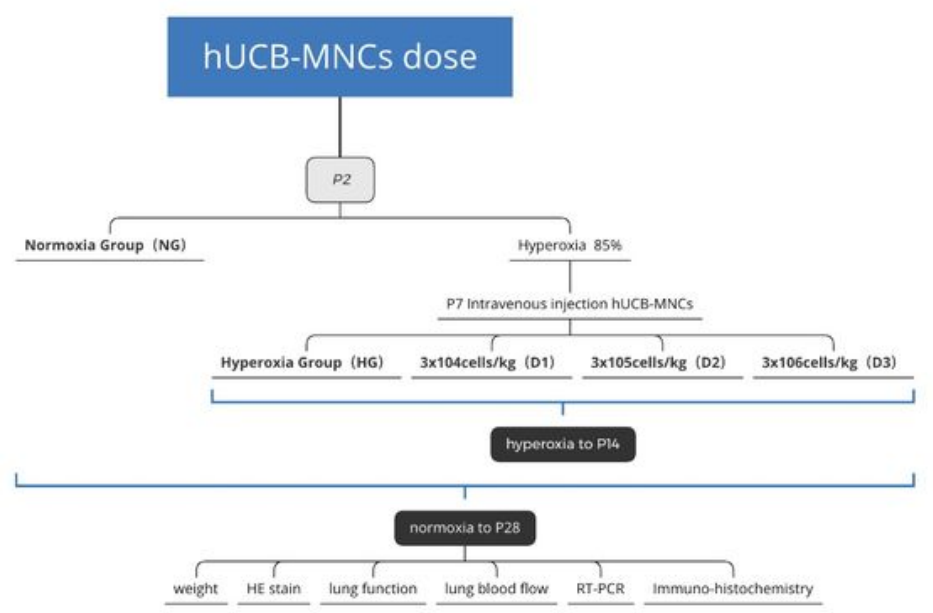

b

C
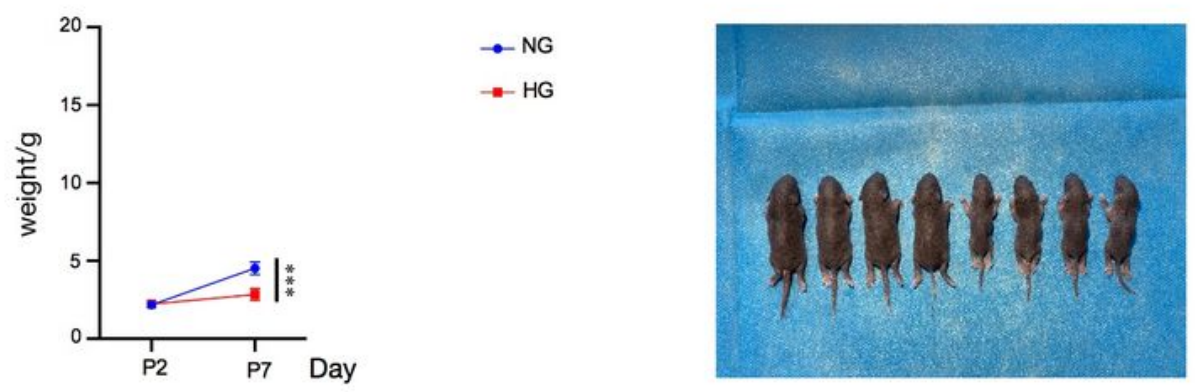

d

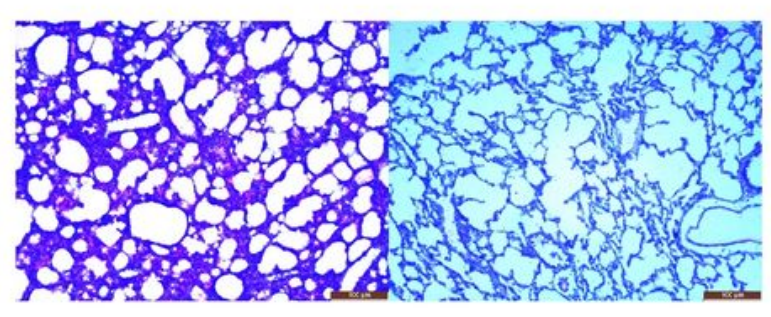

NG

HG

\section{Figure 1}

Hyperoxia induced lung injury in neonatal mice model a. Design. b. Body weight at birth and at P7 in normoxia group (NG) and hyperoxia group (HG). c. Body shape at P7. d.Morphometry for H\&E stain. ${ }^{\star \star \star} p$ $<0.001$ versus NG; ${ }^{* \star} p<0.01$ versus NG; ${ }^{*}<0.05$ versus NG. 


\section{figure 2}

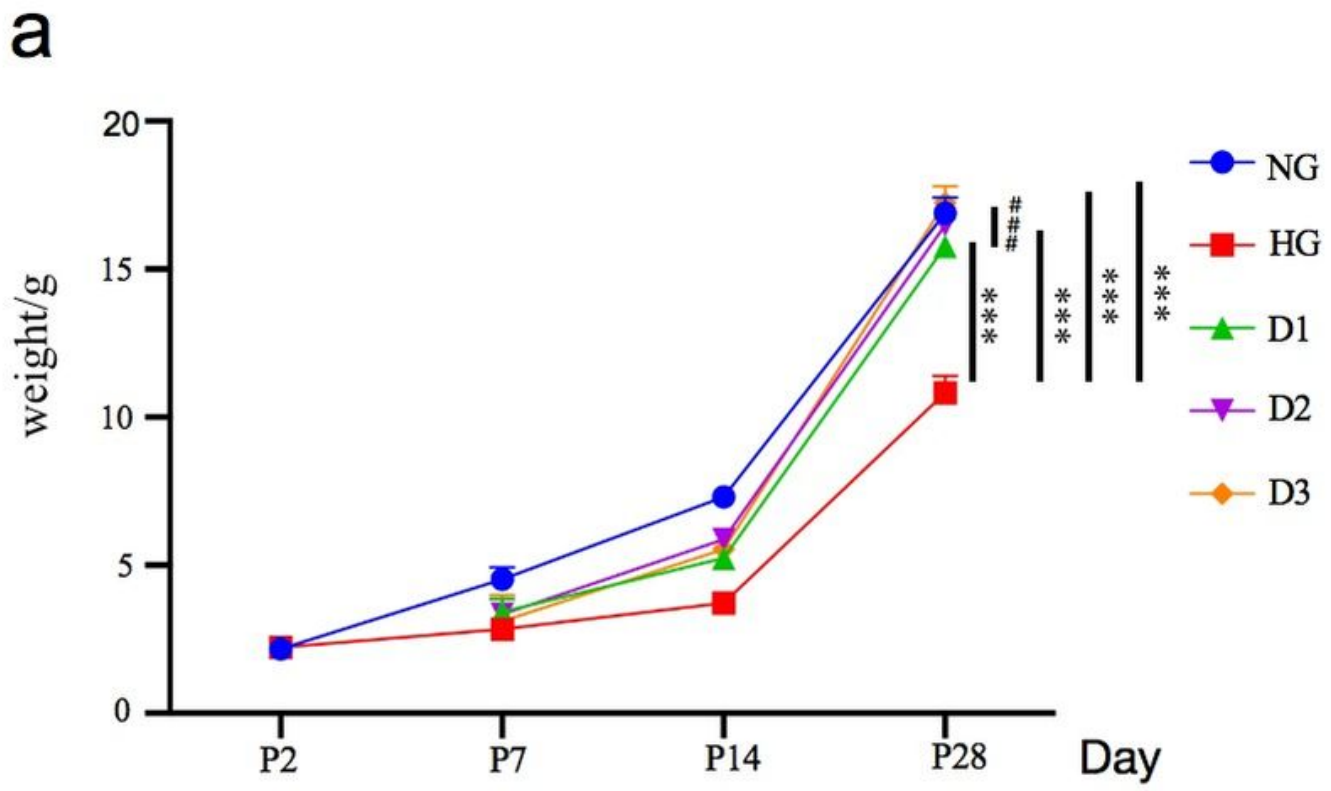

b

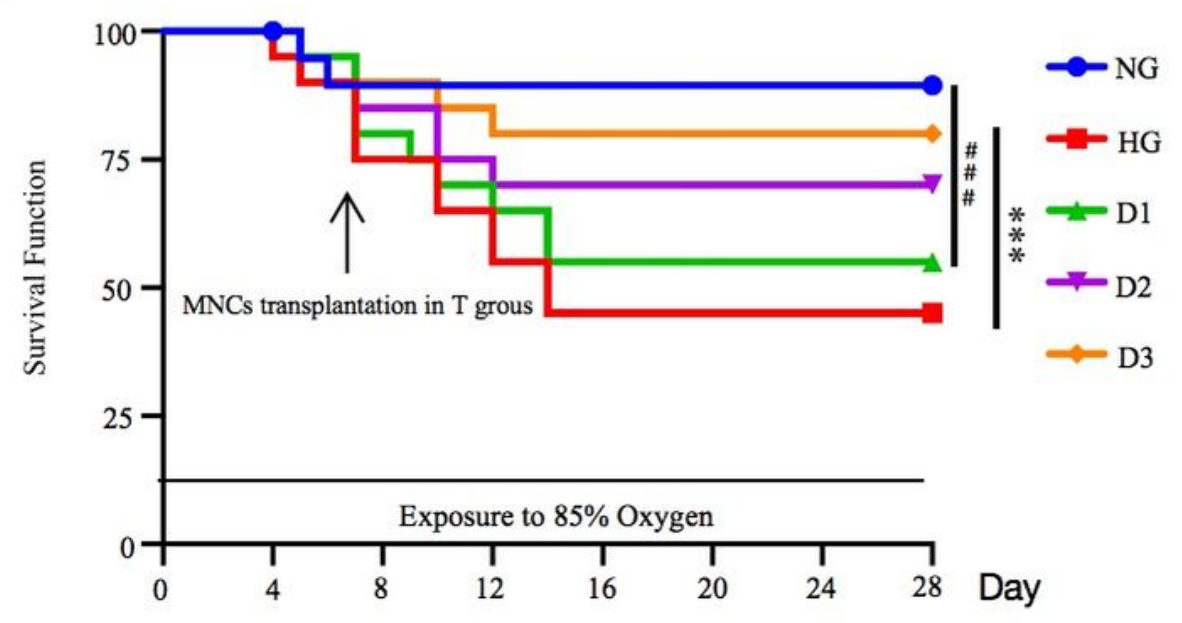

Figure 2

Body weights at birth and postnatal day (P) 7, 14, 28 (a) and Kaplan-Meier survival curve (b). Data are mean $\pm S E M$ for normoxia group (NG), hyperoxia group (HG), hyperoxia exposed mice with $3 \times 104 \mathrm{cells} / \mathrm{kg}$ (D1) MNCs intravenous administration, $3 \times 105$ (D2) MNCs intravenous administration, or 3×106 (D3) MNCs intravenous administration. Data are mean \pm SEM for NG, HG, D1, D2 and D3. ${ }^{\star \star *} p<0.001$ versus HG; ** $p<0.01$ versus HG; ${ }^{*} p<0.05$ versus HG. \#\#\# $p<0.001$ versus NG; \#\# $p<0.05$ versus NG. 


\section{figure 3}

a
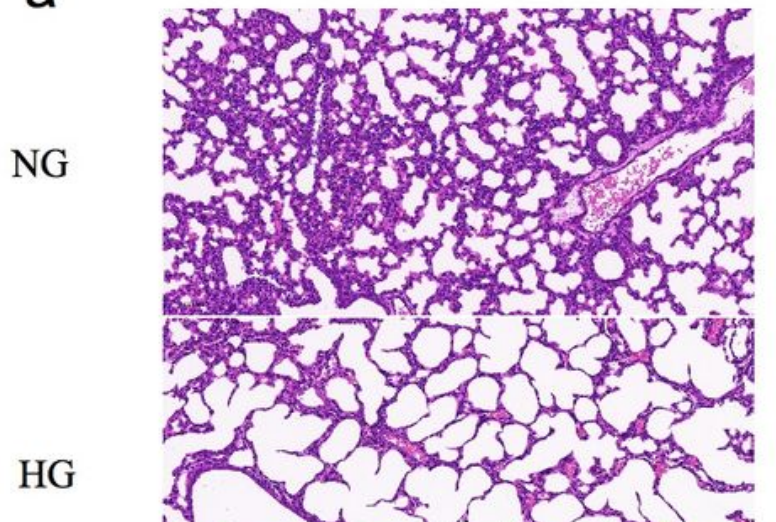

D1

D2

D3

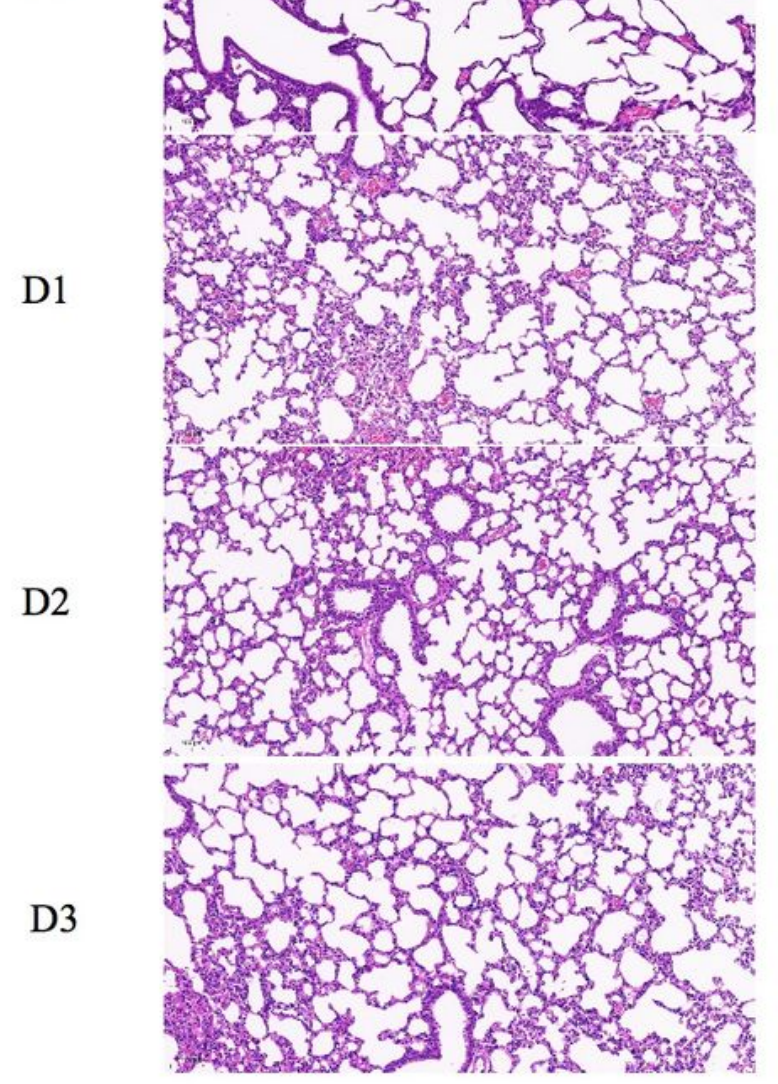

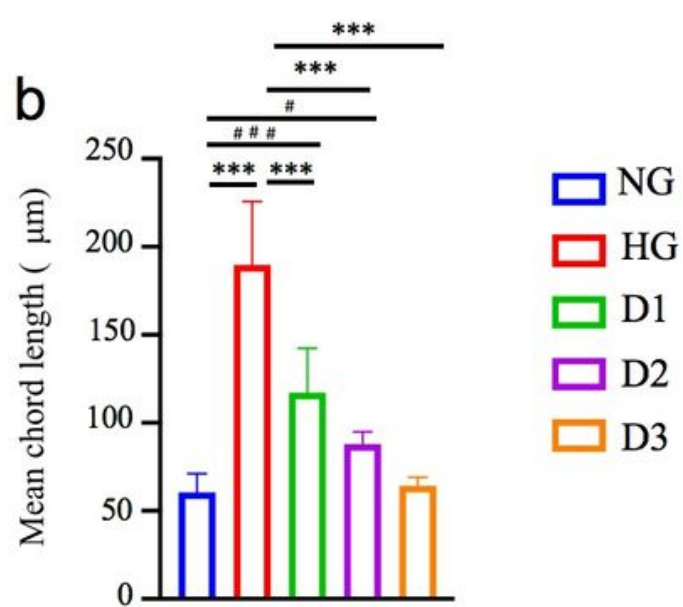
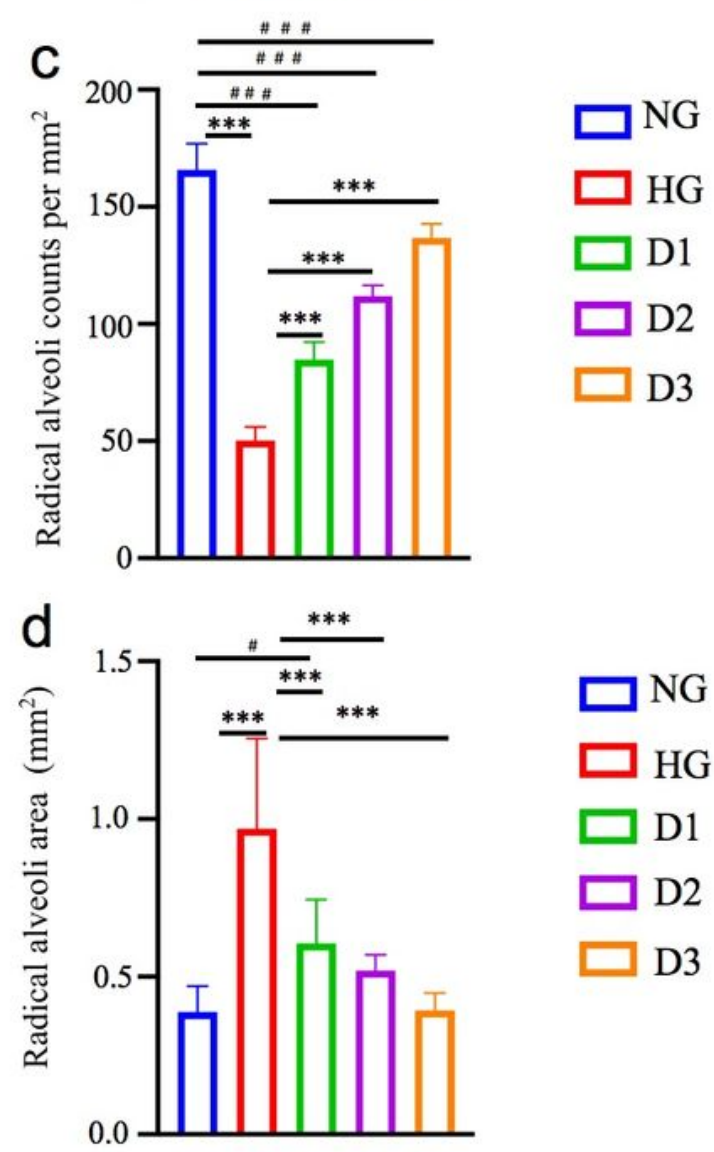

\section{Figure 3}

Morphometric analysis of the P28 mice lung: degree of alveolarization measured by Mean chord length (MCL) (b), Radical alveoli area (RAA) (c) and the radical alveolar counts (RAC) (d). Data are mean \pm SEM for normoxia group (NG), hyperoxia group (HG), hyperoxia exposed mice with $3 \times 104$ cells $/ \mathrm{kg}$ (D1) MNCs intravenous administration, 3×105 (D2) MNCs intravenous administration, or 3×106 (D3) MNCs 
intravenous administration. Data are mean \pm SEM for NG, HG, D1, D2 and D3. ${ }^{\star \star \star} p<0.001$ versus HG; ${ }^{* \star p}$ $<0.01$ versus $H G$; * $p<0.05$ versus $H G$.

\section{figure 4}

a
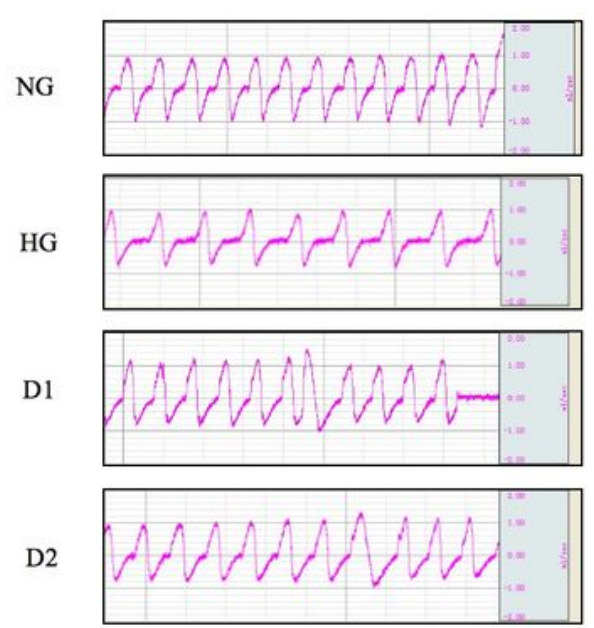

D3

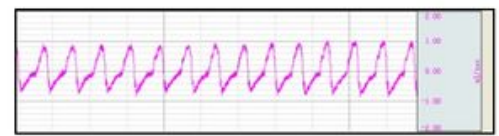

c

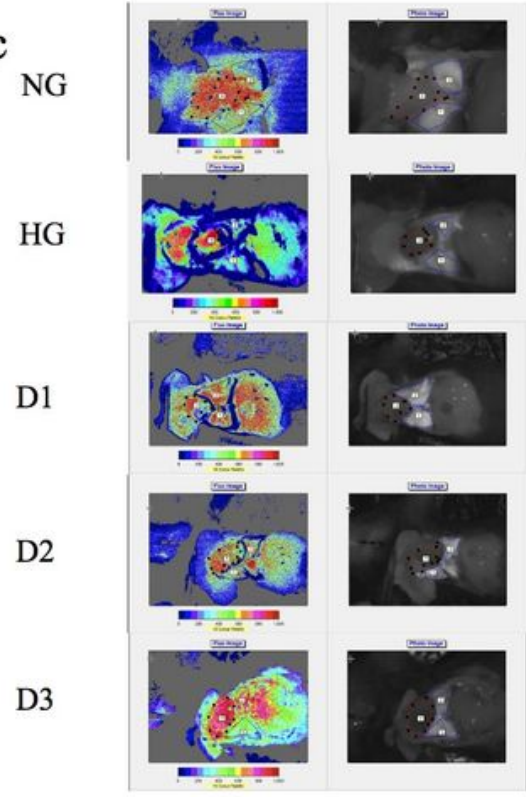

b PIF
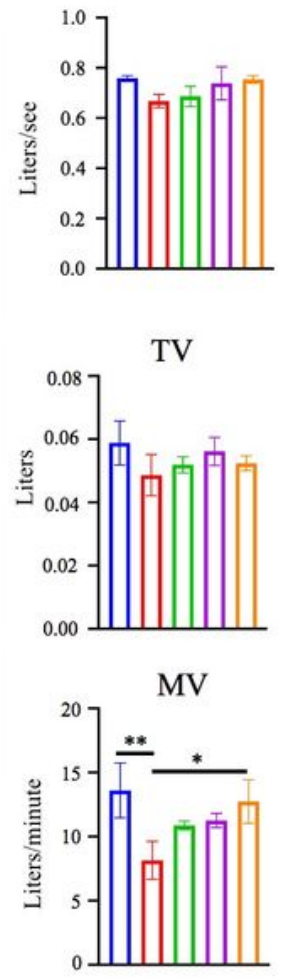

PEF
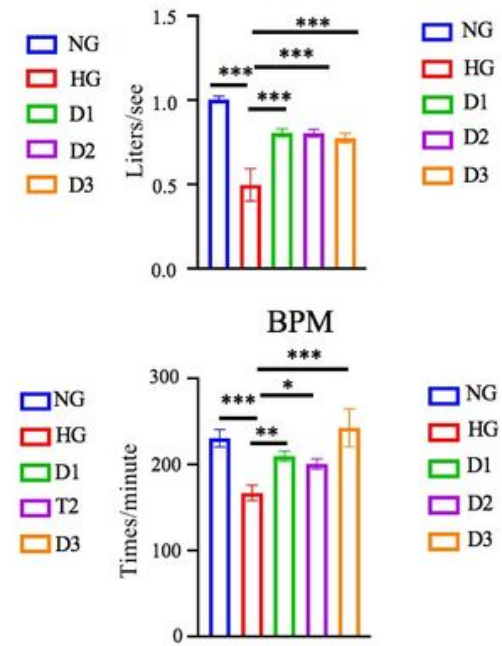

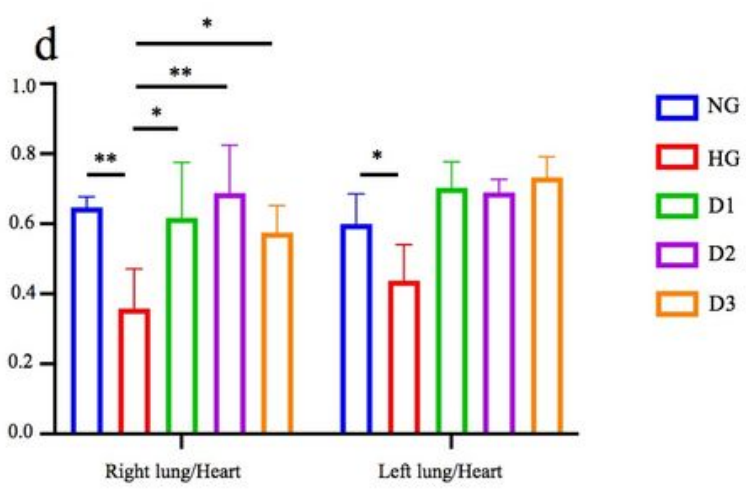

\section{Figure 4}

Pulmonary motion function (a) and blood flow (c) of the P28. Peak inspiratory flow (PIF), peak expiratory flow (PEF), tidal volume (TV), breathing per minute (BPM) and minute volume (MV) (b). Left or right lung/heart blood flow ratio (d). Data are mean \pm SEM for normoxia group (NG), hyperoxia group (HG), 
hyperoxia exposed mice with 3×104cells/kg (D1) MNCs intravenous administration, 3×105 (D2) MNCs intravenous administration, or 3×106 (D3) MNCs intravenous administration. Data are mean \pm SEM for $N G, H G, D 1, D 2$ and D3. *** $p \otimes 0.001$ versus HG; ${ }^{* \star} p<0.01$ versus HG; ${ }^{*} p<0.05$ versus HG.

\section{figure 5}
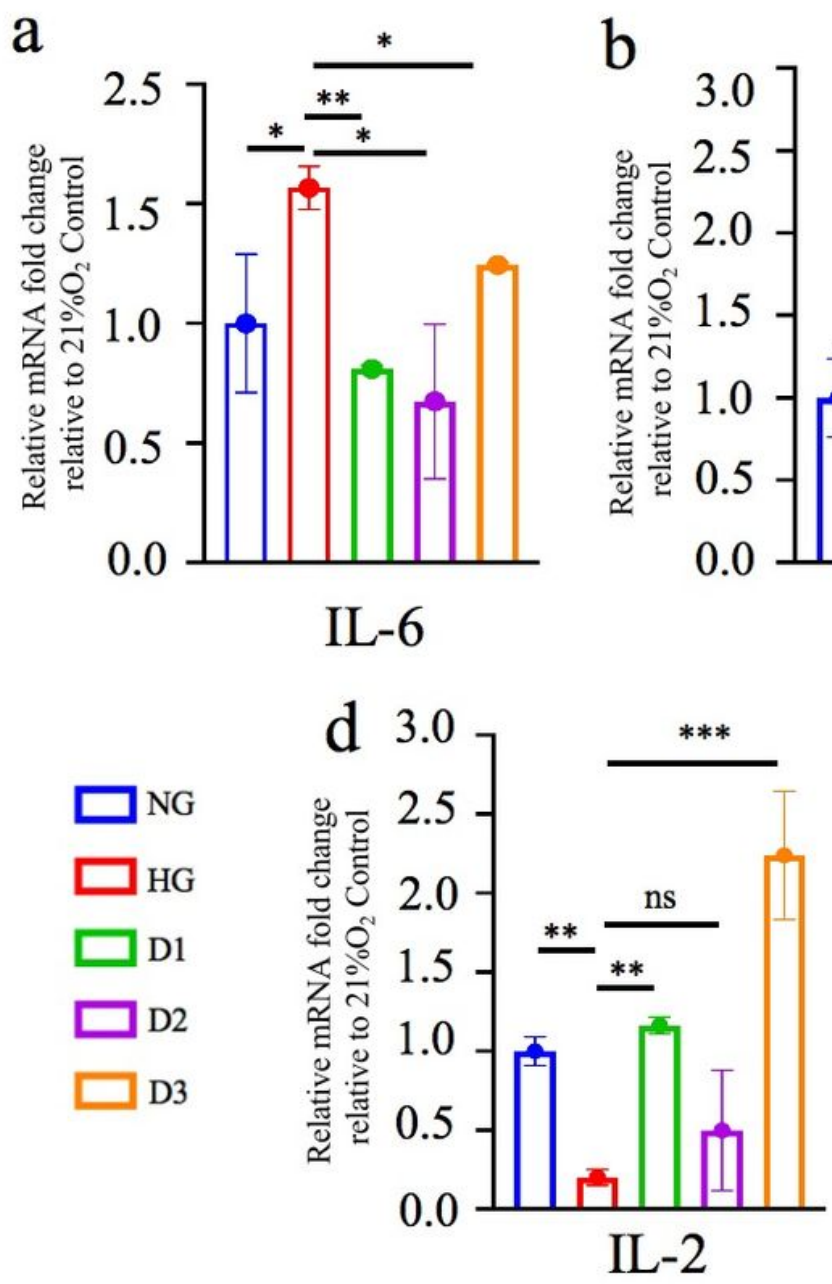

b

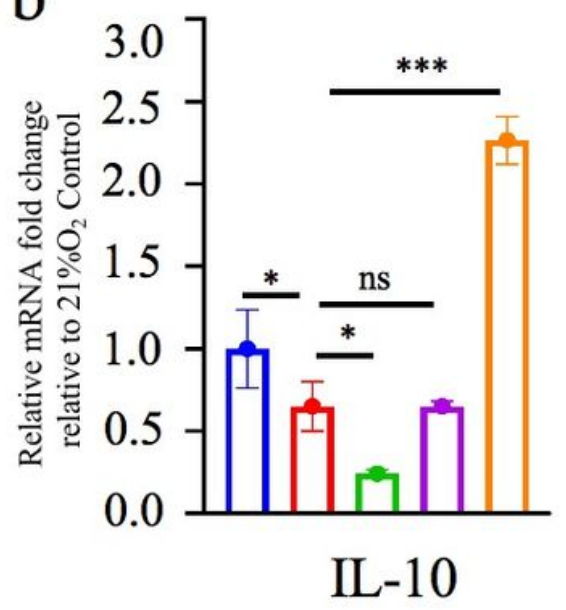

e 6.0

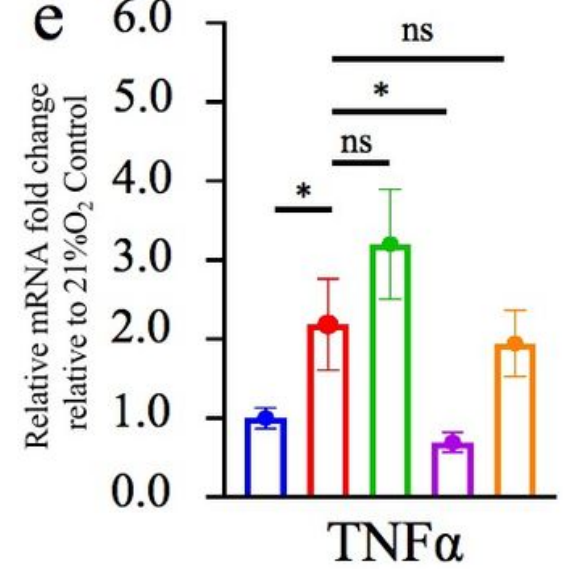

\section{Figure 5}

Cytokine expression in P28 mice lungs. Representative RT-PCR tumor necrosis factor- $a$ (TNF- $a$ ), interleukin-1 $\beta$ (IL-1 $\beta$ ), IL-6, IL-2, and IL-10 in P28 mice lung. Data are mean \pm SEM for NG, HG, D1, D2 and D3. *** $p<0.001$ versus HG; ${ }^{* *} p<0.01$ versus HG; * $p<0.05$ versus HG. \#\#\# $p<0.001$ versus NG; \#\# $p$ $<0.05$ versus NG. 


\section{figure 6}

a

NG

HG

D1

D2

D3
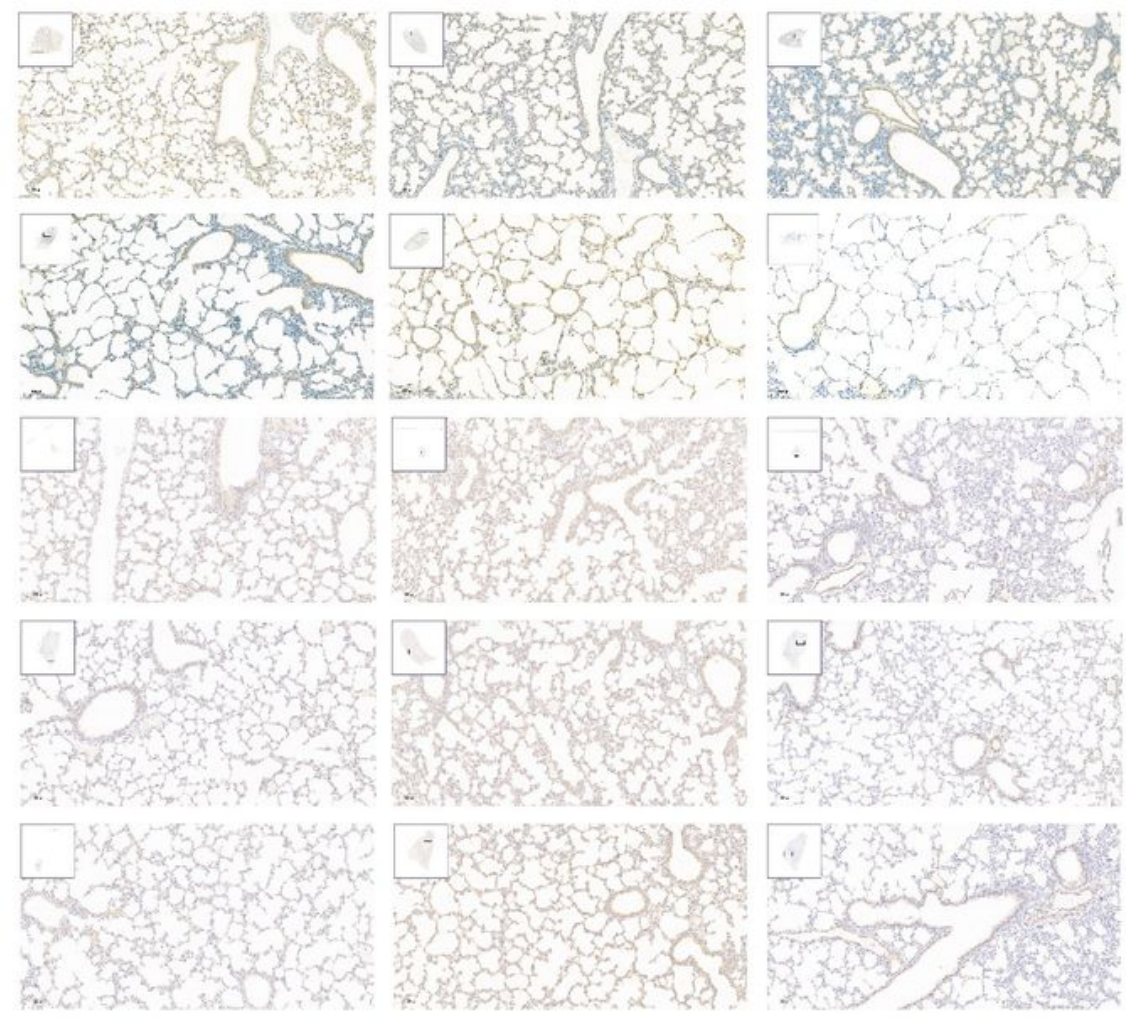

TGF- $\beta$
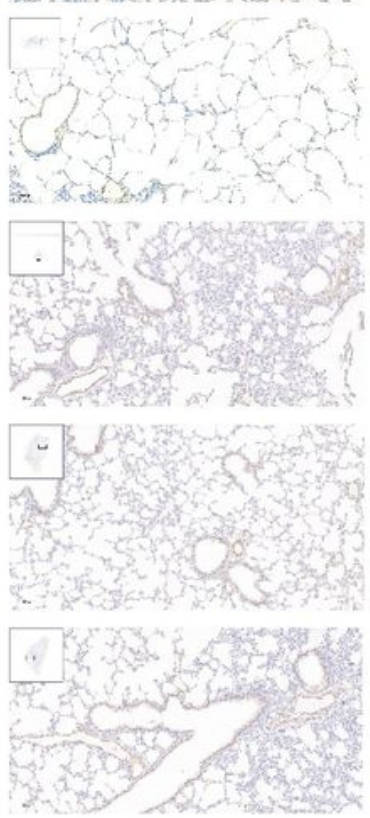

VEGF

b

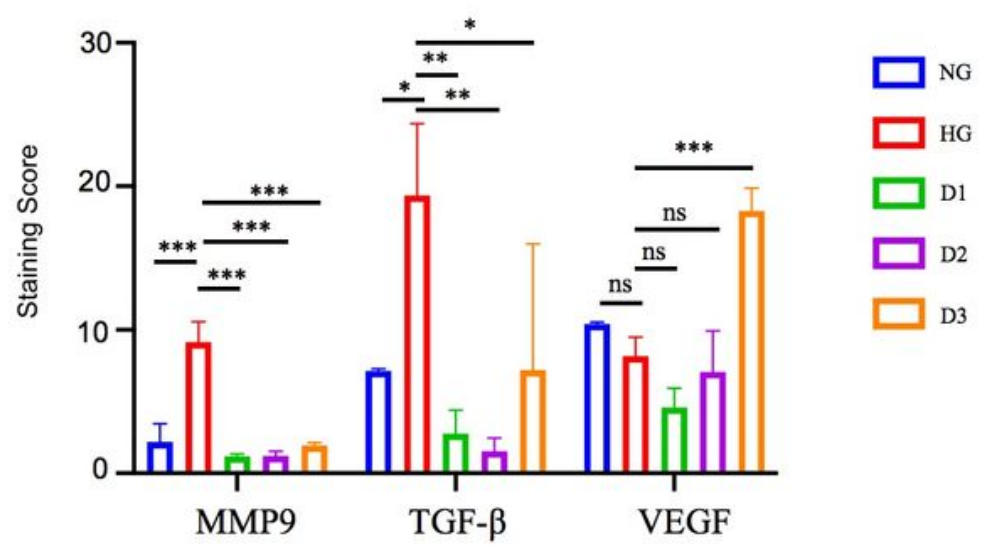

\section{Figure 6}

Immunohistochemical protein level of growth factors. Immunohistochemical protein level of transforming growth factor- $\beta$ (TGF- $\beta$ ), matrix metalloproteinase 9 (MMP9) and vascular endothelial growth factor (VEGF) in P28 mice lung. Data are mean \pm SEM for NG, HG, D1, D2 and D3. ***p $<0.001$ versus HG; ${ }^{\star \star} p<0.01$ versus HG; $p<0.05$ versus HG. \#\#\# $p<0.001$ versus NG; \#\# $p<0.05$ versus NG. 